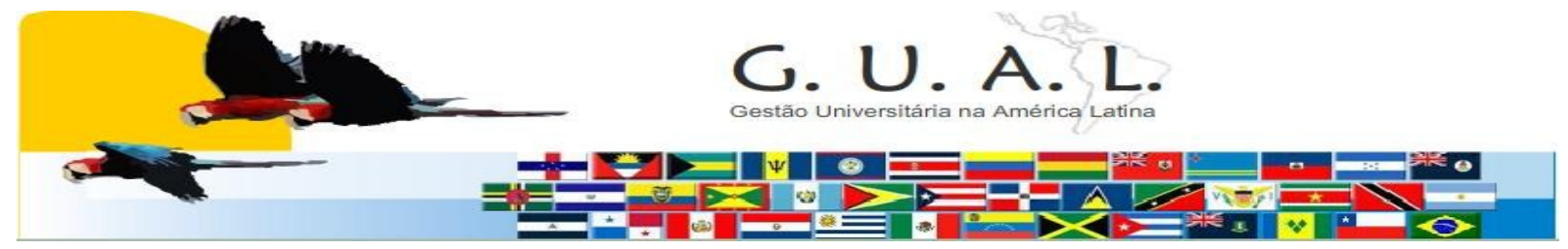

ISSN 1983-4535

\title{
POLÍTICAS DE INCLUSÃO APLICADAS NA UNIVERSIDADE FEDERAL DE SANTA CATARINA: GESTÃO SOCIAL OU GESTÃO ESTRATÉGICA?
}

\author{
Kátia Denise Moreira, Especialista \\ Universidade Federal de Santa Catarina - UFSC \\ katiadenise@yahoo.com.br \\ Mércia Pereira, Especialista \\ Universidade Federal de Santa Catarina - UFSC \\ mercia.pereira@ufsc.br
}

\author{
Sirlene Silveira de Amorim, Especialista \\ Universidade Federal de Santa Catarina - UFSC \\ sirlene.ssa@gmail.com \\ Luís Moretto Neto, Doutor \\ Universidade Federal de Santa Catarina - UFSC \\ moretto@cse.ufsc.br
}

\section{RESUMO}

As políticas de inclusão, aplicadas no âmbito da Universidade Federal de Santa Catarina (UFSC) estão expressas no programa de Ações Afirmativas, o qual trata do sistema de cotas, o Programa Incluir, aplicado para aqueles portadores de necessidades especiais, e o Curso Pré-Vestibular, que visa a democratizar o acesso ao ensino superior. O objetivo da pesquisa é investigar se essas políticas de inclusão são uma prática de gestão social ou se pretendem apenas atender ao definido na gestão estratégica da Instituição. A metodologia está embasada na abordagem científica de natureza predominantemente qualitativa. É descritiva, com base na análise de documentos, obras e relatórios. O resultado evidencia que as políticas de inclusão da UFSC são aplicadas sob a ótica da gestão estratégica; entretanto, verificam-se elementos característicos da inovação social, e também há, em suas origens, alinhamento com o que pretende a gestão social.

Palavras-chave: Gestão estratégica. Gestão social. Inovação social. Políticas de inclusão. 


\section{INTRODUÇÃO}

As políticas de inclusão, apresentadas pelo termo Ações Afirmativas, foram criadas no ano de 1963 pelo governo americano com o intuito de solucionar o problema de segregação racial norte-americano. Contemporaneamente, vários outros países, entre eles o Brasil, adotam tais ações, a fim de promover a "[...] efetiva igualdade de oportunidades a que todos os seres humanos têm direito.” (GOMES, 2001, p. 41).

Tratando especificamente do cenário brasileiro, o campo da educação é um exemplo de aplicação de tais políticas, e esta é a área-tema desta pesquisa, que apresenta um estudo sobre a relação existente entre a Gestão Social e as Políticas de Inclusão aplicadas na Universidade Federal de Santa Catarina (UFSC).

No ambiente de estudo, a aplicação de políticas de inclusão é observada em programas como: o de Ações Afirmativas, propriamente dito, o qual trata do sistema de cotas, o Incluir, aplicado para aqueles portadores de necessidades especiais, e o Curso Pré-Vestibular, que visa a democratizar o acesso ao ensino superior. Entretanto, conforme já mencionado, esta pesquisa intenciona discutir se tais políticas de inclusão estão alinhadas à gestão social ou se pretendem apenas atender ao definido na gestão estratégica da Instituição. Nesse sentido, o objetivo da pesquisa é investigar se as políticas de inclusão aplicadas na Instituição estão alinhadas à prática de gestão social.

Justifica-se este estudo pelo que está proposto na missão da Instituição: “[...] construção de uma sociedade justa e democrática e na defesa da qualidade de vida (UFSC 2010, p.17)”, ou seja, investiga-se se a democracia - ponto relevante da gestão social, “[...] no processo da gestão social, acorde com o agir comunicativo - dialógico, a verdade só existe se todos os participantes da ação social admitem sua validade [...]” (TENÓRIO, 2008b, p.27) está de fato presente nas políticas de inclusão praticadas na UFSC.

Com base nesse contexto e considerando a importância do tema no universo do ensino superior de Santa Catarina, bem como a justificativa da realização desta pesquisa, propõe-se a seguinte estrutura de teorização: Gestão Universitária, Gestão Social; Gestão Estratégica e Políticas de Inclusão. 


\section{FUNDAMENTAÇÃO TEÓRICA}

\subsection{Gestão universitária}

As primeiras ações para a implementação do ensino superior no Brasil aconteceram apenas no século XIX, ou seja, de forma tardia, em comparação a outros países da América Latina, nos quais a Coroa Espanhola desde o século XVI já havia criado instituições para o ensino em tal nível. Os estudantes brasileiros, para obterem seus diplomas, deslocavam-se para a metrópole Portugal; na Colônia - Brasil, os estudos ficavam a cargo dos jesuítas da Companhia de Jesus, os quais trabalhavam a catequização dos indígenas em aldeias, formação do clero em seminários e a educação de filhos da nobreza em colégios reais (OLIVE, 2002).

De acordo com Olive (2002), data de 1920 a primeira universidade brasileira, localizada no Rio de Janeiro. Desde aquele momento, a educação superior vem sendo construída e ajustada ao marco legal vigente, e muitas das demandas sociais da educação superior são dimensões de natureza qualitativa e quantitativa.

A educação superior está devidamente regulamentada na Constituição da República Federativa do Brasil de 1988, em seu Capítulo III, Seção I, que dispõe sobre a educação de forma geral, mas que em seu Artigo 207, por exemplo, trata especificamente da autonomia de instituições que ofertam o ensino em estudo.

A Lei 9.394, de 1996, Lei de Diretrizes e Bases da Educação Nacional, define em seu contexto a estrutura da Educação Superior de graduação e pós-graduação. O Ensino Superior, de acordo com o Decreto n. ${ }^{\circ}$ 5.773, de 9 de maio de 2006, define que as instituições de educação superior, de acordo com sua organização e respectivas prerrogativas acadêmicas, serão credenciadas como faculdades, centros universitários e universidades.

Tratando mais especificamente das universidades, a Lei de Diretrizes e Bases da Educação Nacional define que tais instituições são pluridisciplinares de formação dos quadros profissionais de nível superior, de pesquisa, de extensão e de domínio e cultivo do saber humano, que se caracterizam por:

I - produção intelectual institucionalizada mediante o estudo sistemático dos temas e problemas mais relevantes, tanto do ponto de vista científico e cultural, quanto regional e nacional;

II - um terço do corpo docente, pelo menos, com titulação acadêmica de mestrado ou doutorado; 
III - um terço do corpo docente em regime de tempo integral. (BRASIL, 1996).

O Plano Nacional de Educação (PNE - Lei n. ${ }^{\circ}$ 10.172, de 9 de janeiro de 2001), trata da finalidade da universidade, a qual, na sua essência, é a de produzir e disseminar o conhecimento:

[...] a importância que se deve dar às Instituições de Ensino Superior (IES), mormente à universidade e aos centros de pesquisa, erige-se sobre a constatação de que a produção de conhecimento, hoje mais do que nunca e assim tende a ser cada vez mais a base do desenvolvimento científico e tecnológico e que este é que está criando o dinamismo das sociedades atuais. [...] As universidades constituem, a partir da reflexão e da pesquisa, o principal instrumento de transmissão da experiência cultural e científica acumulada pela humanidade. Nessas instituições apropria-se o patrimônio do saber humano que deve ser aplicado ao conhecimento e desenvolvimento do País e da sociedade brasileira. A universidade é, simultaneamente, depositária e criadora de conhecimentos. (grifo nosso).

Nesse sentido, retomando o disposto no artigo 207 da Constituição Federal, o ensino superior obedece ao princípio da indissociabilidade do ensino, da pesquisa e da extensão e tem como uma de suas finalidades, de acordo com o Inciso I do artigo 43 da Lei de Diretrizes e Bases da Educação Nacional "estimular a criação cultural e o desenvolvimento do espírito científico e do pensamento reflexivo [...]”. Em outras palavras, e de acordo com o exposto, considera-se este um âmbito de desenvolvimento de conhecimento.

Sobre o conhecimento, Demo (2008) expõe que a característica da não linearidade do conhecimento o torna um destruidor, que se irá reconstruir, mas de forma provisória, a fim de que possa continuar construindo-se sempre. Isso significa que o ensino superior está inserido em um ambiente de grande complexidade, visto que se apresenta de forma caótica/estruturada: “[...] É caótico no sentido de que seu ser apresenta-se dotado de propriedades não lineares ou de dinâmica também ambígua/ambivalente. É estruturado porque, na maior desordem, sempre é possível divisar alguma ordem” (DEMO, 2008, p.13). Complementa-se tal declaração, observando que o espaço de atuação do ensino superior apresenta as características apresentadas por Demo (2008) para definir a complexidade, isto é, é dinâmico, não linear, reconstrutivo, passa por um processo dialético evolutivo, é irreversível, intenso, e é fato que a ambiguidade/ambivalência é uma constante.

Considerando os elementos apontados por Demo (2008), em conjunto com o inciso VI do artigo 43 da Lei de Diretrizes e Bases da Educação Nacional, “estimular o conhecimento 
dos problemas do mundo presente, em particular os nacionais e regionais, prestar serviços especializados à comunidade e estabelecer com esta uma relação de reciprocidade" (BRASIL, 1996), entende-se o espaço do ensino superior como local propício à prática da inovação, inclusão e gestão social.

\subsection{Gestão social}

A gestão social vem atualmente adquirindo maior notoriedade no contexto administrativo. Entretanto há de se ter o cuidado no entendimento do verdadeiro significado da expressão, pois, de acordo com França Filho:

A emergência súbita do termo na agenda do debate público e mediático indica duas tendências. A primeira diz respeito a sua própria banalização. [...] A segunda, mais do que uma tendência, reflete uma constatação: a maior visibilidade do termo está associada à própria ascensão da discussão sobre o terceiro setor que chama atenção para o papel de organizações privadas atuando com objetivos públicos. (FRANÇA FILHO, 2008, p. 27).

Tenório (2008a, p.39), no mesmo sentido, diz que “o conceito de gestão social [...] tem sido objeto de estudo e prática muito mais associado à gestão de políticas sociais, de organizações do terceiro setor, de combate à pobreza e até ambiental [...]”.

A gestão social foi mencionada pela primeira vez, no âmbito nacional, nos anos noventa, quando o neoliberalismo inclui-se na política econômica brasileira e tem como objetivo a "[...] discussão e possibilidade de uma gestão democrática, participativa, quer na formulação de políticas públicas, quer naquelas relações de caráter produtivo" (TENORIO, 2008a, p.39). Em outras palavras, o que se pretende é uma gestão na qual a igualdade seja praticada, ou seja, todos os atores sociais têm, no contexto da gestão social, isonomia participativa. Tenório explica tal afirmação quando expõe:

No processo da gestão social, acorde com o agir comunicativo - dialógico, a verdade só existe se todos os participantes da ação social admitem sua validade, isto é, verdade é a promessa de consenso racional ou, a verdade não é uma relação entre o indivíduo e a sua percepção do mundo, mas sim um acordo alcançado por meio da discussão crítica, da apreciação intersubjetiva. (TENÓRIO, 2008b, p.27, grifo do autor).

De acordo com Tenório (2008a), a gestão social está embasada no estudo e discussão de pares de palavras-categorias: Estado-sociedade; capital-trabalho; gestão estratégica-gestão 
social e cidadania deliberativa. Em relação aos dois primeiros pares, a proposta é inverter as posições, destacando-se assim o papel da sociedade e do trabalho, historicamente coadjuvantes na relação. Ramos (1981) explica tal relação quando argumenta que, de modo geral, a sociedade tem seus desejos e necessidades voltados para aquilo que o mercado determina, tanto que até o que se oferece aos estudantes de administração e mesmo para aqueles das ciências sociais, é uma teoria fundamentada “[...] nos pressupostos da sociedade centrada no mercado [...]" (RAMOS, 1981, p. XI). Nesse sentido, o autor propõe uma mudança no pensamento organizacional, um modelo alternativo, no qual o indivíduo possa participar das relações de forma a atingir a autorrealização ${ }^{1}$. Essa nova teoria é denominada pelo autor como abordagem substantiva da teoria organizacional ${ }^{2}$, a qual se alinha aos pressupostos da gestão social quando da busca pela inclusão do indivíduo, destacando sua importância nas relações.

A cidadania deliberativa "[...] significa, em linhas gerais, que a legitimidade das decisões deve ter origem em processos de discussão, orientados pelos princípios da inclusão, do pluralismo, da igualdade participativa, da autonomia e do bem comum" (TENÓRIO, 2008a, p. 41).

Complementando a afirmação de Tenório (2008a), vale ressaltar que a Constituição da República Federativa do Brasil trata a cidadania como um dos princípios fundamentais e ainda fortalece a participação do cidadão brasileiro na gerência do País quando explicita que: "Todo o poder emana do povo, que o exerce por meio de representantes eleitos ou diretamente, nos termos desta constituição" (BRASIL, 1998, p.6). Em outras palavras, na teoria o povo brasileiro é responsável pelas decisões a serem tomadas, as quais acontecem em uma esfera pública; isso é a cidadania deliberativa.

Outro ponto a destacar é o viés democrático presente naquilo que propõe a cidadania deliberativa; em outras palavras, se aplicada de forma eficaz à cidadania deliberativa, faz aquilo que Demo (2001, p. 13) define como controle democrático “[...] capacidade da população de manter sob controle o estado e o mercado, de tal sorte que prevaleça o bem

\footnotetext{
${ }^{1}$ Autorrealização - elemento constituído da ação racional substantiva - processo de concretização do potencial inato do indivíduo, como complementados pela satisfação. (SERVA, 1997, p. 22).

2 Abordagem substantiva - Preocupa-se, sistematicamente, com os meios de eliminação de compulsões desnecessárias agindo sobre as atividades humanas nas organizações econômicas e nos sistemas sociais em geral. (RAMOS, 1981, p.135).
} 
comum". Ainda, segundo o autor, esta seria a forma de colocar "o estado a serviço da sociedade, mantendo-o como genuíno “serviço público” (DEMO, 2001, p.13).

Novamente é possível aplicar o proposto por Ramos (1982) sobre gestão, ou seja, por meio da abordagem substantiva da teoria organizacional, o indivíduo participa das relações de forma mais ativa, sem que os processos decisórios administrativos sejam fundamentalmente econômicos, mas sim assumem um caráter mais social, respeitando as atividades substantivas ${ }^{3}$ do cidadão. Tenório complementa tal ideia quando expõe:

A cidadania deliberativa une os cidadãos em torno de um autoentendimento ético. O âmago da cidadania deliberativa consiste precisamente numa rede de debates e de negociações, a qual deve possibilitar a solução racional de questões pragmáticas, éticas e sociais. (TENÓRIO, 2008a, P.44).

O par antagônico - gestão estratégica - gestão social - é apresentado por Tenório (2008a) de modo a enfatizar o monólogo do primeiro em relação ao coletivismo proposto pelo segundo. A gestão estratégica está alinhada ao mercado, à concorrência, ao lucro, a exclusões, às relações perde-ganha, enquanto a gestão social está para a solidariedade, cooperação, concordância, inclusão e relações ganha-ganha.

De acordo com o exposto, observa-se que a gestão social trata de um processo no qual todos os atores sociais participam das decisões que irão atender às necessidades de uma determinada sociedade, enquanto na gestão estratégica a coalizão dominante é quem define o melhor para a sociedade.

\subsection{Gestão estratégica}

O tema estratégia teve sua inserção no âmbito das organizações após os anos 50 nas tentativas de reconstrução do pós-guerra (CAMARGOS; DIAS, 2003). Até aquela data, a preocupação dos gestores restringia-se aos fatores internos das organizações; já a partir dos

\footnotetext{
${ }^{3}$ Sobre as atividades substantivas, Serva (1997, p.19) explica que para Guerreiro Ramos a racionalidade substantiva seria um atributo natural do ser humano que reside na psique. Por meio dela os indivíduos poderiam conduzir a sua vida pessoal na direção da autorrelização, contrabalanceando essa busca de emancipação com o alcance da satisfação social, ou seja, levando em conta também o direito dos outros indivíduos de fazê-lo. As chaves para esse balanceamento seriam o debate racional e o julgamento éticovalorativo das ações.
}

Rev. GUAL., Florianópolis, Edição especial 2011, p.251-273. 
anos 50, a complexidade do mundo empresarial aumentou, passando a exigir um perfil gerencial mais empreendedor, respostas mais rápidas e corretas à ação de concorrentes.

Porter (2011) apresenta o conceito de estratégia como a criação de uma posição única e valiosa que engloba um conjunto diferente de atividades. A essência do posicionamento estratégico é a de escolher atividades diferentes das dos rivais. Essa ideia de estratégia tem um caráter deliberativo, em que a cúpula escolhe as estratégias com base nos fins e meios que decide atingir.

Para Porter (2011), os aspectos caracterizadores da gestão estratégica consideram: eficiência operacional não é estratégia; para uma empresa ultrapassar os rivais terá de proporcionar maior valor aos consumidores ou criar valor a custos mais baixos, ou fazer as duas coisas; a estratégia depende das atividades únicas, ou seja, escolher deliberadamente um conjunto diferente de atividades para fornecer uma combinação única de valor; uma posição estratégica sustentável requer trade-offs, eles criam a necessidade de escolha e impõem limites àquilo que uma empresa oferece; por fim, a adaptação motiva a vantagem competitiva e a sustentabilidade. As tomadas de decisão sobre o posicionamento devem determinar como as atividades se relacionarão entre si.

Mintzberg (2011), como transposição às ideias de Porter (2011), considera que as estratégias também podem ter caráter emergente. Nessa visão, a estratégia tem o sentido de uma linha de ação que só é percebida como estratégica pela organização à medida que ela vai desenrolando-se ou até mesmo depois que já aconteceu.

Ghoshal et al (2005) apresentam cinco configurações diferentes e complementares para a estratégia que ficou denominada como 5P's. Como plano, a estratégia introduz a noção de intenção e enfatiza o papel de liderança consciente. Como pretexto, introduz a ideia de intencionalidade, resgatando a ideia deliberativa da estratégia. Como padrão realizado, centrase sobre a ação efetiva e introduz a noção de qual estratégia que pode emergir. Como posição, introduz o contexto ambiental encorajando a considerar questões de competição, cooperação e podendo reforçar a importância da manipulação. Como perspectiva, é lembrado que estratégia nada mais é do que conceito focando sobre o aspecto interno da organização.

Em suma, a importância maior da gestão estratégica está no fato de se constituir em um conjunto de ações administrativas que possibilitam aos gestores de uma organização 
mantê-la integrada ao seu ambiente e no curso correto de desenvolvimento, assegurando-lhe atingir seus objetivos e sua missão (CAMARGOS; DIAS, 2003).

Observa-se que a gestão estratégica está alinhada às ações desenvolvidas pelas organizações no sentido de atingir uma missão interna, ou seja, as decisões são tomadas em prol daquilo que melhor lhes convém.

Analisando-se o contexto da gestão social e da gestão estratégica, questiona-se em qual situação encontram-se as políticas de inclusão da UFSC. Em outras palavras, trata-se de artifícios para atender ao que o governo entende como melhor para a sociedade (gestão estratégica), ou foram estabelecidas com base no que a sociedade em conjunto deliberou como necessidades (gestão social).

\subsection{Políticas de inclusão}

As políticas de inclusão são apresentadas pelo termo Ações Afirmativas, as quais foram criadas pelo Presidente John Fitzgerald Kennedy, no ano de 1963, com o intuito de solução para o problema de segregação racial norte-americano, ou seja, o objetivo era promover a igualdade entre negros e brancos naquele país (AMARO, 2005). Entretanto, vale dizer que tal política tentava reverter situações criadas pelo próprio governo quando do impedimento aos negros ao acesso às melhores escolas e oportunidades de trabalho.

Na década de 70, o termo passa a ter uma conceitualização mais abrangente. Vinculouse a ele a ideia de igualdade de oportunidades para todos, por meio, por exemplo, da obrigatoriedade no cumprimento de cotas de acesso em instituições educacionais e também no mercado de trabalho (GOMES, 2001).

Assim, os ideais da citada política passam por mudanças, deixando a restrição das questões raciais para alcançar o sentido da inclusão em todas as esferas, fato que ganhou projeção internacionalmente. De acordo com os fatos históricos, vários países adotaram tal política para atender a grupos discriminados em seus domínios, como, por exemplo, Índia, Moscou, Israel, Alemanha, Nigéria, África do Sul, Colômbia e Canadá, entre outros.

No Brasil, as ações afirmativas tiveram início em 1980, com iniciativas no âmbito da educação, quando, com o apoio da Igreja Católica, foram criados cursos pré-vestibulares para jovens negros e os de baixa renda.

A partir do exposto, entende-se por Ações Afirmativas o definido por Sarmento: 
Medidas públicas ou privadas, de caráter coercitivo ou não, que visam promover a igualdade substancial, através da discriminação positiva de pessoas integrantes de grupos que estejam em situação desfavorável, e que sejam vítimas de discriminação e estigma social. Elas podem ter focos muito diversificados, como as mulheres, os portadores de deficiência, os indígenas ou os afros descendentes [sic], e incidir nos campos mais variados, como educação superior, acesso a empregos privados ou cargos públicos, reforço à representação política ou preferências na celebração de contratos. (SARMENTO, 2006, p. 130).

Complementam Sarmento e Gomes quando expõem que, em síntese,

[...] trata-se de políticas e de mecanismos de inclusão concebidos por entidades públicas, privadas e por órgãos dotados de competência jurisdicional, com vistas à concretização de um objetivo constitucional universalmente reconhecido - o da efetiva igualdade de oportunidades a que todos os seres humanos têm direito. (SARMENTO; GOMES, 2001, p.41).

Analisando o contexto apresentado, é possível dizer que as políticas de inclusão assemelham-se à gestão social naquilo que é seu propósito mais geral - a igualdade entre todas as partes envolvidas em um processo. Os objetivos fundamentais da República Federativa do Brasil, dispostos no Artigo 3. ${ }^{\circ}$ da Constituição, são exemplos de que a Nação brasileira, teoricamente, tende para uma gestão mais social, conforme demonstra o quadro a seguir:

\section{Quadro 1}

Relações entre a Constituição da República Federativa do Brasil e a Gestão Social

\begin{tabular}{|c|c|}
\hline $\begin{array}{c}\text { Constituição da República Federativa } \\
\text { do Brasil (1988) - Objetivos }\end{array}$ & $\begin{array}{c}\text { Elementos caracterizadores da } \\
\text { Gestão Social }\end{array}$ \\
\hline $\begin{array}{c}\text { I - Construir uma sociedade livre, justa e } \\
\text { solidária. }\end{array}$ & Solidariedade. \\
\hline II - Garantir o desenvolvimento nacional. & Pensamento coletivo. \\
\hline $\begin{array}{c}\text { III - Erradicar a pobreza e a marginalização e } \\
\text { reduzir as desigualdades sociais e regionais. }\end{array}$ & Cooperação. \\
\hline $\begin{array}{c}\text { IV - Promover o bem de todos, sem } \\
\text { preconceitos de origem, raça, sexo, cor, } \\
\text { identidade e quaisquer outras formas de } \\
\text { discriminação. }\end{array}$ & Inclusão. \\
\hline
\end{tabular}

Fonte: Elaborado pelas autoras, com base em Tenório (2008) e BRASIL (1988).

Entretanto, apesar de as políticas de inclusão ou mesmo a gestão social se apresentarem de forma implícita nos objetivos da Lei maior do País, sabe-se que a 
implementação de tais ações é tarefa árdua, visto o que Tenório (2008a) aponta como elementos caracterizantes da gestão social.

[...] o conceito de gestão social não está atrelado às especificidades de políticas públicas direcionadas a questões de carência social ou de gestão de organização do denominado terceiro setor, [é sim] uma possibilidade de gestão democrática onde o imperativo categórico não é apenas o eleitor e/ou contribuinte, mas sim o cidadão deliberativo; não é só a economia de mercado, mas também a economia social; não é o cálculo utilitário, mas o consenso solidário; não é o assalariado como mercadoria, mas o trabalhador como sujeito; não é somente a produção como valor de troca, mas igualmente como valor de uso; não é tão-somente a responsabilidade técnica, mas, além disso, a responsabilidade social; não é a res privata, mas sim res publica; não é o monólogo, mas, ao contrário, o diálogo. (TENORIO, 2008a, p.54-55, grifo do autor).

Em síntese, apesar das dificuldades de desvinculação da sociedade em relação à racionalidade instrumental, ou seja, aquela que “[...] torna o social, o político, o cultural, o ecológico, o estético, subordinados ou reféns do econômico compreendido em termos estritamente mercantis" (TENÓRIO, 2008, p.31), muito se tem feito no sentido contrário, ou seja, há pessoas, grupos e entidades trabalhando sob a lógica da racionalidade substantiva. Tal afirmação tem como exemplo, no cenário brasileiro, a educação, mais especificamente a inclusão no ensino superior, tema deste artigo.

Cabe ainda destacar nesta pesquisa aquilo de que trata a inovação social, prática que ocorre quando determinados projetos, que visam a atender as variadas necessidades de uma determinada sociedade, encontram espaço para a concretização. De acordo com Oliveira (2001, apud COUTINHO, 2010), as ações inovadoras, socialmente, atendem às demandas da população e desencadeiam mecanismos de inclusão para aqueles sempre excluídos (grifo nosso).

Segundo Coutinho (2010, p. 8), para que a inovação social ocorra, é necessário estabelecer alguns princípios, quais sejam: "a busca da coerência para o trabalho em equipe entre as estruturas institucionais envolvidas e a definição de um sistema integrado de funcionamento, que permita articular as estratégias institucionais, de planejamento, sistematização e implantação, de forma a torná-lo sustentável”.

Isso significa que a inovação social busca promover a inclusão e associa-se ao exposto por Tenório (2008a, p.54) de que a “[...] a gestão social deve ser praticada como um processo 
intersubjetivo, dialógico, onde todos têm direito à fala. E este processo deve ocorrer em um espaço social, na esfera pública”. Tenório (2008a, p.54) acrescenta: “[...] entendemos gestão social como o processo gerencial decisório deliberativo que procura atender às necessidades de uma dada sociedade, região ou sistema social específico".

De acordo com o apresentado, é possível dizer que as políticas de inclusão assemelham-se à inovação social, pois tendem à inclusão daqueles socioeconomicamente menos favorecidos (sempre excluídos), e à gestão social naquilo que é seu propósito mais geral - a igualdade entre todas as partes envolvidas em um processo.

Entretanto, apesar de coincidirem em alguns aspectos, há de se destacar que as políticas de inclusão são determinadas pelo governo (gestão pública), e, sendo assim, "assenta[m]-se numa lógica de poder segundo os parâmetros de uma racionalidade instrumental $^{4}$ e técnica" (FRANÇA FILHO, 2008, p. 32), enquanto na gestão social "o econômico aparece apenas como um meio para a realização dos fins sociais, que podem definir-se também em termos culturais, políticos ou ecológicos, a depender do campo de atuação da organização" (FRANÇA FILHO, 2008, p. 32).

Ainda sobre a gestão social, França Filho (2008, p. 30) sugere que “[...] além do Estado, a gestão das demandas e necessidades do social pode se dar via a própria sociedade, através das suas mais diversas formas e mecanismos de auto-organização, especialmente o fenômeno associativo".

Nesse sentido, o autor manifesta que a prática da gestão social é tarefa árdua, visto que há certamente uma série de desafios a serem superados, entre os quais o autor destaca:

Em resumo, são estes os dois grandes desafios que se impõem à gestão social. De um lado, superar uma cultura política tradicional que permeia o mundo das organizações sociais e empreender parcerias efetivas entre sociedade civil e poderes públicos que reconheçam e estimulem o real potencial dos grupos implicados, para além de uma mera atitude de instrumentalização da ação. Do outro, a necessidade de construção de um arcabouço metodológico que preencha os requisitos básicos de uma gestão genuinamente comprometida com o social. (FRANÇA FILHO, 2008, p. 33$34)$.

\footnotetext{
4 “[...] ação baseada no cálculo, orientada para o alcance de metas técnicas ou de finalidades ligadas a interesses econômicos ou de poder social, através da maximização dos recursos disponíveis." (SERVA, 1997, p. 22).
}

Rev. GUAL., Florianópolis, Edição especial 2011, p.251-273. 
Em síntese, apesar das dificuldades de desvinculação da sociedade em relação àquilo que trata a racionalidade instrumental, muito se tem feito no sentido contrário, isto é, há pessoas, grupos e entidades trabalhando sob a lógica da racionalidade substantiva.

No cenário brasileiro, tal afirmação tem, como exemplo, a educação, mais especificamente a inclusão no ensino superior, tema desta pesquisa, que faz um estudo sobre a proximidade entre aquilo que propõe a gestão social e as políticas de inclusão aplicadas na UFSC, a fim de desvendar se essas políticas são práticas de gestão social ou apenas atendem ao definido na gestão estratégica da Instituição.

\subsection{A gestão social e as políticas de inclusão aplicadas na Universidade Federal de Santa Catarina}

A Universidade Federal de Santa Catarina (UFSC), criada em 1960, tendo como fundamento legal para sua criação a Lei n. ${ }^{\circ} 3.849$, de 18 de dezembro de 1960, iniciou seus trabalhos com 847 alunos e 49 docentes, vindos de faculdades isoladas entre as quais se destacam: Farmácia e Odontologia, Direito e Ciências Econômicas. No decorrer de seus cinquenta anos, a Instituição modernizou-se e, certamente, inovou-se. Hoje, a UFSC conta com onze centros de ensino e três campi, nos quais são desenvolvidos o ensino, a pesquisa e a extensão, empenhados no cumprimento da seguinte missão:

Produzir, sistematizar e socializar o saber filosófico, científico, artístico e tecnológico, ampliando e aprofundando a formação do ser humano para o exercício profissional, a reflexão crítica, a solidariedade nacional e internacional, na perspectiva da construção de uma sociedade justa e democrática e na defesa da qualidade de vida. (UFSC, 2010, p.17).

Nesse sentido, na perspectiva da construção de uma sociedade justa e democrática e na defesa da qualidade de vida, por meio das políticas de inclusão, a UFSC busca proporcionar aos menos favorecidos socialmente às possibilidades descritas em sua missão.

As políticas de inclusão aplicadas no âmbito da UFSC são: o programa de Ações Afirmativas, propriamente dito, o qual trata do sistema de cotas, o Programa Incluir, aplicado para aqueles portadores de necessidades especiais, e o Curso Pré-Vestibular. Todos os Programas estão diretamente ligados à Pró-Reitoria de Ensino de Graduação (PREG) e são gestionados pela Diretoria de Gestão e Desenvolvimento Acadêmico (DGA), no setor de Supervisão dos Programas de Inclusão. 


\section{POLÍTICAS DE INCLUSÃO APLICADAS NA UNIVERSIDADE FEDERAL DE SANTA CATARINA: GESTÃO SOCIAL OU GESTÃO ESTRATÉGICA?}

No ano de 2007, a UFSC criou o Programa de Ações Afirmativas, o qual foi aprovado pelo órgão máximo deliberativo, por meio da Resolução Normativa n. ${ }^{\circ}$ 008/CUn/2007, em 10 de julho de 2007, estabelecendo que seriam destinados vinte por cento do total de vagas do Concurso Vestibular para os candidatos de escola pública, dez por cento aos candidatos negros e cinco vagas aos indígenas, (será criada uma nova vaga anualmente até 2013). O Programa de Ações Afirmativas da Universidade constitui-se em instrumento de promoção dos valores democráticos, de respeito à diferença e à diversidade socioeconômica e étnicoracial, mediante a adoção de uma política de ampliação do acesso aos seus cursos de graduação e de estímulo à permanência na Universidade (UFSC, 2007).

O Programa Incluir, aplicado para aqueles portadores de necessidades especiais, busca a acessibilidade na educação superior. O projeto foi desenvolvido pelo Ministério de Educação, criado para viabilizar a implantação ou consolidação de núcleos de acessibilidade nas universidades federais do Brasil.

$\mathrm{Na}$ UFSC, o projeto foi desenvolvido para dar atenção especial aos alunos com deficiência matriculados desde o ano 2006. O fim prioritário é criar Núcleos de Acessibilidade para garantir a participação dessas pessoas, especialmente no que se refere aos equipamentos e recursos pedagógicos necessários na Universidade. Considera-se que esses dois elementos são os que permitem o acesso e permanência dos alunos com deficiência no Ensino Superior. A Universidade atende hoje, em todos os níveis de ensino - graduação (Entrevista 1 e 5), pós-graduação stricto sensu (Entrevista 3 e 4), ensino fundamental e médio (Entrevista 6) e educação infantil (Entrevista 7), aproximadamente 466 alunos, sendo que as deficiências consideradas pelo projeto são: auditiva, física, visual, Síndrome de Asperger, Síndrome de Down, autismo, Transtorno do Déficit de Atenção com Hiperatividade, dislexia e deficiências múltiplas (UFSC, 2008).

Desde 1990, estão sendo desenvolvidos projetos nessa área. Alguns deles já implementados, como por exemplo: a criação e organização do Curso de Licenciatura LetrasLIBRAS; a criação do Núcleo de Investigação sobre o Desenvolvimento Humano (NUCLEIND); o projeto Sábado no Campus, que consiste em esportes adaptados. Também há dois projetos de extensão, um deles sobre o assessoramento aos professores do Colégio de Aplicação pelos alunos de UFSC, e o outro consiste na criação de um Laboratório de Comunicação Alternativa e Aumentativo do Colégio de Aplicação (UFSC, 2008). 
O projeto proposto para o Programa Incluir pretende consolidar o lugar da UFSC como instituição de referência na inclusão de alunos com deficiência. Segundo o documento enviado ao MEC, articulando essas ações e concentrando uma parte delas no NUCLEIND, será possível criar e consolidar um órgão articulador de atividades. Algumas dessas ações já estão sendo desenvolvidas no Colégio de Aplicação e no Núcleo de Desenvolvimento Infantil, ambos ligados ao Centro de Ciências da Educação (CED) (UFSC, 2008).

Os núcleos de inclusão ampliarão o acesso das pessoas com deficiência a todos os espaços da Universidade, garantindo sua participação nas atividades desenvolvidas na Instituição, como projetos de pesquisa, intercâmbio e cooperação técnico-científica. Será por meio deles que o MEC e as universidades procurarão a permanência e integração dos alunos deficientes, para afiançar a acessibilidade universal (UFSC, 2008).

Criado no ano de 2003, na gestão do Reitor Rodolfo Pinto da Luz, o curso prévestibular UFSC é fruto da iniciativa do professor Otavio Augusto Auler Rodrigues, membro da sociedade civil, conjugada por uma percepção da própria UFSC, por meio da comissão permanente do vestibular, de que os candidatos isentos da taxa de inscrição no concurso vestibular não conseguiam aprovação (Entrevista 1).

A partir de 2008, por meio de um convênio com o governo do Estado de Santa Catarina, o projeto alcança condições de expansão da sua área de abrangência e alunos atendidos, aliando seu objetivo de inclusão à busca do Estado em garantir acesso aos estudantes das escolas públicas. O pré-vestibular deixa de ser uma ação isolada para constituir-se em política de Estado. Por esse convênio, o Estado é responsável por todo o custo operacional do programa (docentes, material didático, cessão das instalações didáticas, entre outros), e recebe a contrapartida da Universidade na sua coordenação executiva. (Entrevista 1).

A partir da visibilidade, promovida por sua atuação alcançou parcerias como Banco do Brasil e Rede Brasil Sul de Comunicação (RBS TV), as quais foram estabelecidas ao longo do tempo com o objetivo de apoiar e financiar ações específicas, como aulões, simulados, entre outros. (Entrevista 2).

Nos seus oito anos de atuação o pré-vestibular UFSC tem apresentado uma constante de crescimento em relação aos alunos atendidos, cidades abrangidas e percentual de inclusão. Em relação ao percentual de inclusão os números são predominantemente crescentes, nunca 
sendo percebida uma inclusão inferior a 14\% desde sua origem. Sendo que no ano de 2011 o Pré-Vestibular UFSC alcançou 58\% de alunos incluídos. (UFSC, 2011a).

Atualmente, o Pré-Vestibular UFSC conta com 50 funcionários diretamente vinculados ao projeto, com uma oferta de 5.000 vagas, distribuídas por 28 cidades catarinenses. (Entrevista 2).

\section{PROCEDIMENTOS METODOLÓGICOS}

A pesquisa realizada com o objetivo de investigar se as políticas de inclusão da UFSC são consideradas práticas de gestão social, ou se pretendem apenas atender ao definido na gestão estratégica da Instituição, apresenta uma abordagem científica de natureza predominantemente qualitativa, justificada nas palavras de Godoy (1995b, p. 62), quando diz que essas políticas "têm como preocupação fundamental o estudo e a análise do mundo empírico em seu ambiente natural".

Segundo a perspectiva de que um fenômeno pode ser mais bem compreendido no contexto em que ocorre e do qual é parte, devendo ser analisado numa perspectiva integrada, esta pesquisa busca a compreensão ampla do fenômeno pesquisado a partir da "obtenção de dados descritivos sobre pessoas, lugares e processos interativos pelo contato direto do pesquisador com a situação estudada, procurando compreender os fenômenos segundo a perspectiva dos sujeitos, ou seja, dos participantes da situação em estudo" (GODOY, 1995b, p. 58).

Segundo a classificação apontada por Godoy (1995a), uma abordagem qualitativa oferece três diferentes estratégias de pesquisa: a documental, o estudo de caso e a etnografia. Baseada na premissa de que "a necessidade de se utilizar a estratégia de pesquisa estudo de caso deve nascer do desejo de entender um fenômeno social complexo", a resposta ao objetivo desta pesquisa é resultado de uma estratégia de estudo de caso, o qual investiga um fenômeno contemporâneo dentro de seu contexto real. As fronteiras entre o fenômeno e o contexto não são claramente evidentes e múltiplas fontes de evidências são utilizadas (YIN, 2008).

O propósito fundamental do estudo de caso é analisar intensivamente uma dada unidade social, fato que de acordo com Yin (2010), consiste em uma investigação aprofundada do fenômeno em seu contexto de vida real. 
Quanto às fontes de evidência para a análise do fenômeno, estas são variadas, ocorrendo por análise documental, registros em arquivos, observação e artefatos físicos, tendo como técnicas fundamentais a observação e a entrevista.

Com a preocupação de representar todos os atores do fenômeno, a pesquisa tratou intencionalmente de atores das políticas de inclusão e também por análise documental.

As categorias de análise para a realização do trabalho, considerando seu tema central, políticas de inclusão e a gestão social, foram: gestão universitária (já que é esse o tipo de ambiente em análise), gestão social propriamente dita (para identificar seus aspectos caracterizantes), inovação social (espaço de prática da gestão social), gestão estratégica (fazendo o contraponto da gestão social) e políticas de inclusão (objetivo-fim do programa pesquisado).

A pesquisa limita-se na disponibilidade dos dados apresentados, bem como na forma como eles foram dispostos. A dificuldade em encontrar as pessoas-chave para entrevista foi outro fato limitador, mas que, no entanto, não prejudicou a resposta ao problema pesquisado.

\section{CONSIDERAÇÕES FINAIS}

Como resultado, este estudo trouxe reflexões sobre os temas: gestão social, gestão estratégica, inovação social e políticas de inclusão, inseridos na gestão universitária de uma instituição específica. A investigação de tais elementos possibilitou responder se as políticas de inclusão aplicadas na UFSC estão alinhadas à prática de gestão social ou se pretendem apenas atender àquilo definido na gestão estratégica da Instituição.

Observa-se que a UFSC, por sua própria missão, é espaço propício à prática da inovação e da gestão social:

Produzir, sistematizar e socializar o saber filosófico, científico, artístico e tecnológico, ampliando e aprofundando a formação do ser humano para o exercício profissional, a reflexão crítica, a solidariedade nacional e internacional, na perspectiva da construção de uma sociedade justa e democrática e na defesa da qualidade de vida. (UFSC, 2010, p.17).

Confirma-se que a Instituição é ambiente de diálogo, nele a comunidade tem direito a manifestar-se, e todo esse processo ocorre em uma esfera pública. As políticas de inclusão em 
estudo são, inclusive, manifestações da vontade de uma sociedade, na qual a UFSC está inserida e tem como objetivo a democratização do acesso ao ensino superior.

No entanto, constata-se que o Programa de Ações Afirmativas tem suas origens em políticas públicas governamentais que objetivam erradicar as desigualdades. O Programa Incluir atende ao disposto no Programa Nacional de Assistência Estudantil (PNAES), em síntese, “[...] ampliar as condições de permanência dos jovens na educação superior pública federal" (BRASIL, 2010), e o Pré-Vestibular, criado no ano de 2003, visando a ampliar sua abrangência, une-se, por meio de convênio, ao Governo de Estado de Santa Catarina. Com base em tais observações, percebe-se que as políticas de inclusão da UFSC tendem para a minimização das carências sociais da comunidade, fato que não é propósito da gestão social.

A relação entre políticas de inclusão e a gestão social no ambiente de estudo fica evidenciada somente na fala de alguns atores pesquisados. Exemplo disso é o fato de o programa pré-vestibular originar-se da iniciativa civil, ato que vai ao encontro do que expõe Tenório (2008a, p. 39) sobre a gestão social ser a “[...] discussão e possibilidade de uma gestão democrática, participativa, quer na formulação de políticas públicas, quer naquelas relações de caráter produtivo". Tal ação acorda ainda com outro aspecto caracterizador da gestão social, a cidadania deliberativa. Tenório (2008, p. 41) declara: “[...] a legitimidade das decisões teve origem em processos de discussão, orientados pelos princípios da inclusão, do pluralismo, da igualdade participativa, da autonomia e do bem comum”.

Todavia, vale ressaltar que a Instituição pratica, por meio das políticas de inclusão, o definido pela inovação social, ou seja, as ações inovadoras socialmente atendem às demandas da população e desencadeiam mecanismos de inclusão para aqueles sempre excluídos (OLIVEIRA, 2001, apud COUTINHO, 2010). Tal fato é comprovado pela análise da qualidade inclusiva, baseada no conceito de Sarmento (2006) de que as políticas de inclusão têm caráter coercitivo ou não, visando a promover a igualdade substancial, mediante discriminação positiva de pessoas integrantes de grupos que estejam em situação desfavorável, que sejam vítimas de discriminação e estigma social, e têm respaldo nos números, apresentados no contexto deste estudo.

Analisando outros aspectos, entre eles a estrutura organizacional e o aporte financeiro, constata-se que as políticas de inclusão estão alinhadas ao proposto pela gestão estratégica. Exemplo de tal constatação é a verificação, por exemplo, da existência de convênios e 
contratos para manutenção dos programas, e uma estrutura funcional caracterizada por chefes e subordinados, confirmando o definido por Camargo e Dias (2003) para tal tipo de gestão: “conjunto de ações administrativas que possibilitam aos gestores de uma organização mantêla integrada ao seu ambiente e no curso correto de desenvolvimento, assegurando-lhe atingir seus objetivos e sua missão”. Além disso, os objetivos, ainda que não sejam financeiros, focam o incremento do sistema produtivo agindo predominantemente como uma extensão do governo para suas ações.

Por fim, e de acordo com o apresentado, obtém-se como resultado da pesquisa que as políticas de inclusão praticadas pela UFSC são uma prática de gestão social apenas quando da iniciativa de criação, entretanto são inovadoras sociais, pois essencialmente visam à inclusão. Contudo, estão predominantemente alinhadas à gestão estratégica, fato descrito no próprio Plano de Desenvolvimento Institucional da Instituição, quando trata da inclusão social.

\section{REFERÊNCIAS}

AMARO, S. A questão racial na assistência social: um debate emergente. Serviço Social e Sociedade: Ed. Cortez, São Paulo, n. 81, 2005. p. 58-81.

BRASIL, Constituição da República Federativa do Brasil (1988). Disponível em: $<$ http://www.planalto.gov.br/ccivil_03/constituicao/constitui\%C3\%A7ao.htm $>$. Acesso em: 13 maio 2011.

. Decreto n. ${ }^{\circ}$ 64.824, de 15 de julho de 1969. Aprova o Plano de Reestruturação da Universidade Federal de Santa Catarina. Disponível em:

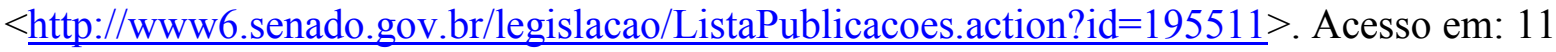
jun. 2010.

. Decreto n. ${ }^{\circ}$ 5.773, de 9 de maio de 2006. Dispõe sobre o exercício das funções de regulação, supervisão e avaliação de instituições de educação superior e cursos superiores de graduação e seqüenciais no sistema federal de ensino. Disponível em:

$<$ http://www.planalto.gov.br/ccivil_03/_ato2004-2006/2006/Decreto/D5773.htm>. Acesso em: 11 jun. 2011.

Decreto n. ${ }^{\circ}$ 7.234, de 19 de julho de 2010. Dispõe sobre o Programa Nacional de Assistência Estudantil - PNAES. Disponível em:

$<$ http://www.planalto.gov.br/ccivil_03/_Ato2007-2010/2010/Decreto/D7234.htm>. Acesso em: 11 out. 2011.

. Lei n. ${ }^{0} 5.540$, de 28 de novembro de 1968. Fixa normas de organização e

funcionamento do ensino superior e sua articulação com a escola média, e dá outras

Rev. GUAL., Florianópolis, Edição especial 2011, p.251-273. 


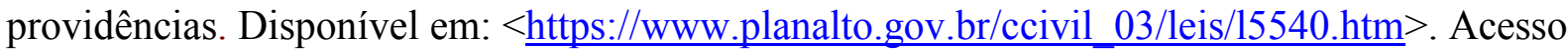
em: 11 jun. 2011.

Lei n. ${ }^{\circ}$ 9.394, de 20 de dezembro de 1996. Lei de Diretrizes e Bases da Educação

Nacional (LDBN). Estabelece as diretrizes e bases da educação nacional.

Disponível em:

$<$ http://www.planalto.gov.br/ccivil_03/Leis/L9394.htm>. Acesso em: 13 maio 2011.

. Lei n. ${ }^{\circ} 10.172$, de 9 de janeiro de 2001. Aprova o Plano Nacional de Educação e dá outras providências. Disponível em:

$<$ http://www.planalto.gov.br/ccivil_03/leis/leis_2001/110172.htm>. Acesso em: 11 jun. 2011.

CAMARGOS, M. A. de; DIAS, A. T. Estratégia, administração estratégica e estratégia corporativa: uma síntese teórica. Caderno de pesquisas em administração. v. 10, n. 1, p. 27 39, jan-mar. 2003.

COUTINHO, E. L. Inovações sócio-economicas e os processos dos cursos técnicos da Rede Federal de Educação Profissional e Tecnológica. In: IV Encontro Nacional de

Pesquisadores em Gestão Social (ENAPEGS), Lavras, p.1-12, mai. 2010. Texto enviado por e-mail às autoras.

DEMO, P. Complexidade e aprendizagem: a dinâmica não linear do conhecimento. 3 . reimpr. São Paulo: Atlas, 2008.

FRANÇA FILHO, G. C. de. Definindo a Gestão Social. In: SILVA JUNIOR, Jeová Torres; MASIH, Rogério Teixeira et al. (Org.). Gestão Social: práticas em debate, teorias em construção. Fortaleza: Imprensa Universitária, 2008.

GHOSHAL, S. et al. O processo da estratégia: conceitos, contextos e casos selecionados. 4 . ed. Porto Alegre: Bookman, 2005.

GODOY, A. S. Pesquisa qualitativa: tipos fundamentais. Revista de administração de empresas. v. 35, n. 3, São Paulo: mai./jun. 1995a. p. 20-29.

, Introdução a pesquisa qualitativa e suas possibilidades. Revista de administração de empresas. v. 35, n. 2, São Paulo: mar./abr. 1995b. p. 57-63

GOMES, J. B. B. Ações afirmativas \& princípio constitucional da igualdade. Rio de Janeiro: Renovar, 2001.

OLIVE, A. C. Histórico da educação superior no Brasil. In: SOARES, Maria Susana Arrosa (Coord.). A educação superior no Brasil. Brasília: DPE Studio2, 2002.

MINTZBERG, H. Patterns in strategy formation. Management science. v. 24, n. 9, p. $934-$ 948, may, 1978. Disponível em: <http://www.jstor.org/pss/2630633>. Acesso em: 7 jul. 2011.

Rev. GUAL., Florianópolis, Edição especial 2011, p.251-273. 
PORTER, M. What is strategy? Harvard Business Review. p. 61-78, nov-dez. 1996.

Disponível em: $<$ http://www.ipocongress.ru/download/guide/article/what is strategy.pdf $>$. Acesso em: 7 jul. 2011.

POLÍTICAS DE INCLUSÃO UFSC. Entrevista 1, maio 2010. Informação verbal.

PRÉ-VESTIBULAR UFSC. Entrevista 2, maio 2010. Informação verbal.

PROJETO INCLUIR UFSC. Entrevista 3, outubro 2011. Informação verbal.

PROJETO INCLUIR UFSC. Entrevista 4, outubro 2011. Informação verbal.

PROJETO INCLUIR UFSC. Entrevista 5, outubro 2011. Informação verbal.

PROJETO INCLUIR UFSC. Entrevista 6, outubro 2011. Informação verbal.

PROJETO INCLUIR UFSC. Entrevista 7, outubro 2011. Informação verbal.

RAMOS, A. G. A nova ciência das organizações. Rio de Janeiro: FGV, 1981.

RODRIGUES, O. A. A. Programa Pré-Vestibular da UFSC. Disponível em:

$<$ http://www.prevestibular.ufsc.br/site2/index.php?link=noticias.html $>$. Acesso em: 17 maio 2010. Entrevista concedida à TV UFSC, Florianópolis, em 02 de agosto de 2009.

SARMENTO, D. A igualdade étnico-racial no Direito Constitucional Brasileiro: discriminação "De Facto", teoria do impacto desproporcional e ações afirmativas. In: CAMARGO, Marcelo Novelino (Org.). Direito Constitucional: leituras complementares. Salvador: Juspodivm, 2006.

SERVA, M. R. de O. A racionalidade substantiva demonstrada na prática administrativa. Revista de administração de empresas. São Paulo: EAESP/FGV, v. 37, n. 2, 1997. p. 18-30.

TENORIO, F. G. (Re) visitando o conceito de gestão social. In: SILVA JUNIOR, J.T.; MASIH, R. T. et al. (Org.). Gestão Social: práticas em debate, teorias em construção. Fortaleza: Imprensa Universitária, 2008a. p. 39 - 59.

Gestão Social: uma perspectiva conceitual. In: Um espectro ronda o terceiro setor, o espectro do mercado: ensaios de gestão social. Ijuí: Unijuí, 2008b. p. 13-38.

UNIVERSIDADE FEDERAL DE SANTA CATARINA. Relatório de Gestão 2008. Florianópolis: UFSC, 2009.

Plano de Desenvolvimento Institucional 2010 a 2014/ Universidade Federal de

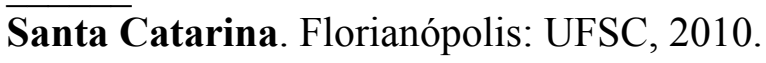

Rev. GUAL., Florianópolis, Edição especial 2011, p.251-273. 
Pré-vestibular da UFSC: inclusão para a vida. Florianópolis: UFSC, 2011a.

. Programa de Ações Afirmativas - PAA. Comissão de Acompanhamento e Avaliação. Disponível em: <http://www.acoes-afirmativas.ufsc.br>. Acesso em: 16 maio $2011 b$.

Programa Pré-Vestibular da UFSC. Inclusão para vida. Disponível em:

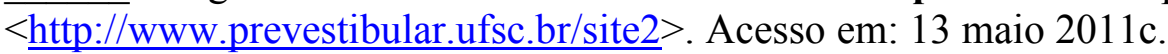

Relatório de Atividades 2010. Pró-Reitoria de Ensino de Graduação.

Disponível em: $<$ http://preg.ufsc.br/files/2011/04/Relat\%C3\%B3rio-de-Atividades-PREG2010-Final.pdf $>$. Acesso em: 16 maio 2011d.

Programa Incluir tenta viabilizar acessibilidade universal na UFSC. Publicado $\overline{\text { em } 27}$ de junho de 2008 pela Agência de Comunicação da UFSC. Disponível em:

$<$ http://noticias.ufsc.br/2008/06/27/programa-incluir-tenta-viabilizar-acessibilidadeuniversal-na-ufsc/> Acesso em: 16 maio 2011.

YIN, R. Estudo de caso. Disponível em:

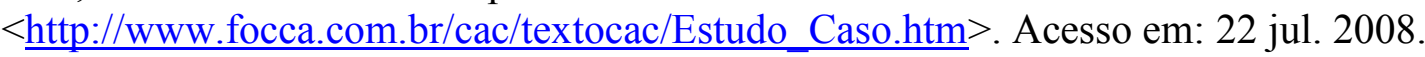

Estudo de caso: planejamento e métodos. Porto Alegre: Bookman, 2010. 


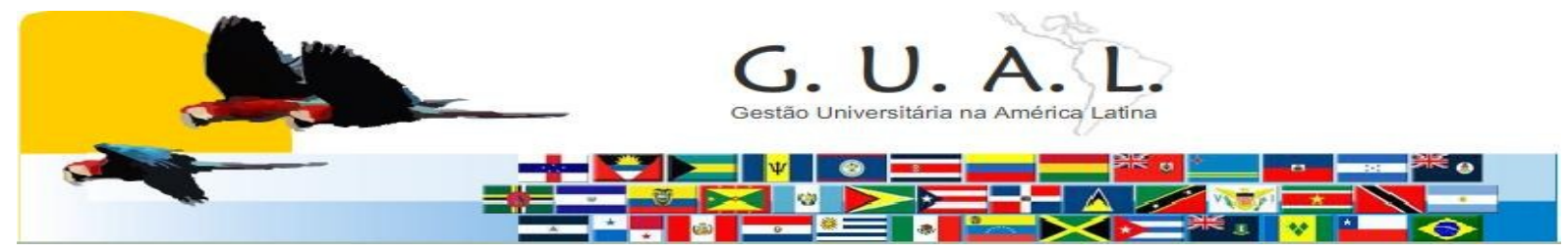

ISSN 1983-4535

\title{
INCLUSION POLICES APPLIED IN THE UNIVERSIDADE FEDERAL DE SANTA CATARINA: SOCIAL MANAGEMENT OR STRATEGIC MANAGEMENT?
}

\author{
Kátia Denise Moreira, Specialist \\ Universidade Federal de Santa Catarina - UFSC \\ katiadenise@yahoo.com.br \\ Mércia Pereira, Specialist \\ Universidade Federal de Santa Catarina - UFSC \\ mercia.pereira@ufsc.br
}

\author{
Sirlene Silveira de Amorim, Specialist \\ Universidade Federal de Santa Catarina - UFSC \\ sirlene.ssa@gmail.com \\ Luís Moretto Neto, Doctor \\ Universidade Federal de Santa Catarina - UFSC \\ moretto@cse.ufsc.br
}

\begin{abstract}
The policies of inclusion applied in the Universidade Federal de Santa Catarina (UFSC), are: The Program of Affirmative Actions, which is related with the quota system; The Program Incluir applied to those people that needs special care and the Pré-Vestibular course, which aims to democratize the university access. The objective of this paper is to investigate whether these policies are included in a social management practice or just want to answer the strategic management of the Institution. The methodology is based on the qualitative approach and It is descriptive, based on analysis of documents, books and reports. The result shows that the UFSC inclusion polices are applied from the perspective of strategic management, however there are distinctive elements of social innovation and also there is, in its origins, relation of the social management.
\end{abstract}

Keywords: Strategic management. Social management. Social innovation. Inclusion policies. 